\title{
Expression of ID2 and Cyclooxygenase 2 Genes in Endometrial Tissues and Their Clinical Significance in the Pathogenesis of Endometrial Polyps
}

\begin{abstract}
RONG WU, FEI GUO'1, YING WANG, JINGJING HU, XIAOFENG XU, WENJUAN YANG, XIAO WU, AYING XING AND ZHAOLIAN WEI*

Reproductive Medicine Center, Department of Obstetrics and Gynecology, The First Affiliated Hospital of Anhui Medical University; Anhui Province Key Laboratory of Reproductive Health and Genetics; Biopreservation and Artificial Organs, Anhui Provincial Engineering Research Center, Hefei, Anhui 230088, ${ }^{1}$ Department of Cardiovascular medicine, The First Affiliated Hospital of USTC, Division of Life Sciences and Medicine, University of Science and Technology of China, Hefei, Anhui 230001, China
\end{abstract}

Wu et al.: Expression of ID2 and COX-2 Genes in endometrial tissues of endometriosis patients

To investigate the expression of Deoxyribonucleic acid binding inhibitor 2 and Cyclooxygenase 2 genes in endometrial polyps patient's endometrial tissues and analyze their clinical significance is the main objective. 38 patients with endometrial polyps who were treated at the minimally invasive gynecologic and reproductive surgery department of our hospital from October 2020 to December 2020 were selected as the test group, and their polyps and the endometrial tissue around the polyps were taken. 36 cases of women who had undergone intrauterine device placement surgery at the same time were scraped from the endometrium before intrauterine device placement. The messenger ribonucleic acid expression and protein levels of deoxyribonucleic acid binding inhibitor 2 and cyclooxygenase 2 in endometrial tissues were detected by quantitative reverse transcription polymerase chain reaction and western blot. In addition, enzymelinked immunosorbent assay was used to detect the levels of vascular endothelial growth factor, tumor necrosis factor-alpha, interleukin 1 beta and cancer antigen 125 and to analyze their relationship with the expression of Deoxyribonucleic acid binding inhibitor 2 and cyclooxygenase 2 in endometrial tissues of endometrial polyp's patients. The results showed that the expression of Deoxyribonucleic acid binding inhibitor 2 and cyclooxygenase 2 messenger ribonucleic acid and protein levels in endometrial tissues were significantly higher in the experimental group compared with the control group, and the difference was statistically significant. Deoxyribonucleic acid binding inhibitor 2 was positively correlated with vascular endothelial growth factor, tumor necrosis factor alpha, interleukin 1 beta and cancer antigen 125 ( $p<0.05)$, while cyclooxygenase 2 was positively correlated with interleukin 1 beta and cancer antigen 125 in the endometrial tissues of patients in the test group. The sensitivity of Deoxyribonucleic acid binding inhibitor 2 was $87.32 \%$, specificity was $64.88 \%$ and cut-off value was 1.68; the sensitivity of cyclooxygenase 2 was $93.15 \%$, specificity was $84.33 \%$ and cut-off value was 2.03. Deoxyribonucleic acid binding inhibitor 2 and cyclooxygenase 2 in endometrial tissues has a high predictive value for the clinical diagnosis of endometrial polyps. Expression is closely related to the development of endometrial polyps, and both may be candidate specific target genes for endometrial polyps, and both may be used as markers for the clinical diagnosis of endometrial polyps.

Key words: Endometrial polyps, deoxyribonucleic acid binding inhibitor 2, cyclooxygenase 2, clinical significance

Endometrial polyps are one of the important causes of irregular menstruation or postmenopausal vaginal bleeding, which can occur at any age. At present, the incidence of endometrial polyps has an increasing trend. Endometrial carcinoma is one of the three major malignant tumors of female genital tract. It is more common in elderly women, accounting for $20 \%$ to $50 \%$ of female reproductive malignant tumors. The pathogenesis of endometrial polyps is still unclear. Studies have shown that endometrial polyps proliferate and form implanted lesions, and the pathogenesis involves adhesion, invasion and angiogenesis ${ }^{[1,2]}$. The 
pathological process is similar to the proliferation and migration of tumor tissue. At present, it is believed that the factors related to cell biology are involved in the development of endometrial polyposis. Studies have shown $^{[3,4]}$ that Deoxyribonucleic acid binding inhibitor 2 (ID2) is related to the proliferation and migration of tumor cells. Cytochrome P450 aromatase (P450arom) is a speed limiting enzyme in estrogen synthesis. Many studies have confirmed that in endometrial polyps and endometrial cancer, the expression of P450arom in local lesions is positively correlated with cyclooxygenase $2(\mathrm{COX}-2)^{[5-7]}$. At present, there are relatively few studies on the expression of ID2 and COX-2 in endometrial tissues of patients with endometrial polyposis. Therefore, this study is to explore the abnormal expression of ID2 and COX-2 in endometrial tissue of patients and their clinical application value.

\section{MATERIALS AND METHODS}

38 patients with endometrial polyps diagnosed and treated in gynecology department of our hospital from October 2020 to December 2020 were selected as the experimental group. All patients were pathologically diagnosed as endometrial polyp, and the corresponding polyp tissues and endometrial tissues around the polyp were taken. In addition, 36 cases of women who underwent insertion of intrauterine contraceptive device in our hospital during the same period were scraped a little endometrium before placing the intrauterine device (IUD). The samples were taken in the first half of the menstrual cycle, and were confirmed as normal endometrial tissue by pathology. All the women did not receive any hormone therapy 3 mo before operation, and there were no estrogen related diseases such as cervical polyps, uterine fibroids, endometrial polyps, etc. there was no significant difference in age between the two groups $(p>0.05)$. The age of patients in the experimental group was $27-45(33.42 \pm 7.14)$ y old, and that of the control group was 25-47 (34.76 \pm 8.30$) \mathrm{y}$ old. This study was approved by the ethics committee of our hospital, and the participants were informed and agreed. Inclusion criteria: Patients who met the diagnostic criteria of endometrial polyps; Patients without hormone therapy; Patients without other serious hormone disorders.
Exclusion criteria: Patients with endometrial tumors, uterine fibroids and other diseases; Patients with severe liver and kidney dysfunction; Patients with severe endocrine, respiratory, digestive and other system diseases; Patients with incomplete clinical data. There was no statistically significant difference in age between the two groups of patients ( $>00.05)$, and they were comparable.

\section{The messenger ribonucleic acid (mRNA) expressions of ID2 and COX-2 in the endometrial tissues of the two groups were detected by Quantitative reverse transcription polymerase chain reaction (qRT- PCR):}

Endometrial tissues of the two groups of patients were selected and two samples were retained. The first specimen was washed with phosphate-buffered saline (PBS) and stored in liquid nitrogen tank. The relative mRNA expression levels of ID2 and COX-2 were detected by real-time fluorescence quantitative PCR. Total RNA was extracted with Trizol kit. The complementary Deoxyribonucleic acid (cDNA) was synthesized with reference to the reverse transcription kit. The reaction system was $20 \mu 1$ : 2x SYBR (Synergy Brands, Inc.) mix $10 \mu 1$, cDNA $1 \mu 1$ and double-distilled water $\left(\mathrm{ddH}_{2} \mathrm{O}\right) 8 \mu \mathrm{l}$. The upstream and downstream primers were $0.5 \mu \mathrm{l}$ each, with Beta-Actin ( $\beta$-actin) as internal reference. The primers were synthesized by Wuhan Biomisp Co., Ltd. And the design of primers is as follows (Table 1). The reaction set-up procedure was as follows: pre-denaturation at $95^{\circ}$ for $1 \mathrm{~min} ; 95^{\circ}$ for $15 \mathrm{~s}, 95^{\circ}$ for $15 \mathrm{~s}, 60^{\circ}$ for $15 \mathrm{~s}, 72^{\circ}$ for $2 \mathrm{~min}$, with a total of 40 cycles. The expression levels of ID2 and COX-2 mRNA in endometrium were quantitatively analyzed by $2^{-\Delta \Delta \mathrm{CT}}$.

\section{The expressions of ID2 and COX-2 were detected by western blot assay:}

The second endometrial tissue samples retained in 1.2.1 were ground and added into protein lysis buffer containing protease inhibitor to extract the total protein of endometrial tissue and determine the total protein. The levels of ID2 and COX-2 protein in endometrium were detected by western blot with $\beta$-actin as internal reference. The detection was carried out strictly in accordance with the operation instructions. The

TABLE 1: PRIMER SEQUENCE

\begin{tabular}{lrr}
\hline Gene & Forward & Reverse \\
\hline ID2 & 5'-TCTACGACATGAACGGCTG-3' & 5'-GGTCCCTGATGTAGTCGAT-3' \\
COX-2 & 5' 'TTCAAATGAGATTGTGGAAAAAT-3' \\
B-actin & 5'-TGCTGTCCCTGTATGCCTCT-3' & 5' -AGATCATCTCTGCCTGAGTATCTT-3' \\
\hline
\end{tabular}


images were taken by Tanon software, and the protein expression level was analyzed semi quantitatively

\section{Detection and observation indicators:}

$5 \mathrm{ml}$ of fasting venous blood was taken from two groups and divided into two parts immediately. One sample was centrifuged, and the supernatant was aspirated. The serum levels of vascular endothelial growth factor (VEGF) and tumor necrosis factor-alpha (TNF- $\alpha$ ) were determined by enzyme-linked immunosorbent assay (ELISA) according to the instructions of the test kit. The other sample was placed in the anticoagulant tube, and the detection reagents of interleukin 1 beta (IL-1 $\beta$ ) and cancer antigen 125 (CA 125) were added. The expression level of IL-1 $\beta$ and CA 125 was detected by colloidal gold method. The levels of VEGF, TNF- $\alpha$, IL-1 $\beta$ and CA 125 in the two groups were observed, and the correlation between the expressions of ID2 and COX-2 and the levels of VEGF, TNF- $\alpha$, IL- $1 \beta$ and CA 125 were analyzed. The correlation between ID2 and COX-2 expression and clinical indicators of patients was compared and analyzed.

\section{Analysis and Statistics:}

Statistical software, Statistical Package for the Social Sciences SPSS 22.0 was used to analyze the data. The quantitative data were represented as mean value \pm standard deviation, and the comparison between the two groups was performed by t test. In addition, the qualitative data were described by the number of cases (\%), while the comparison between groups was conducted by $\mathrm{F}$ test (statistical test). Moreover, the correlation analysis between variables was performed by person correlation analysis. $\mathrm{p}<0.05$ was significant difference.

\section{RESULTS AND DISCUSSION}

The results of PCR showed that compared with the control group, the expressions of ID2 and COX-2 mRNA in the experimental group were significantly increased, and the difference was statistically significant $(\mathrm{p}<0.05)$, as shown in fig. 1 .

According to the results of western blot, the protein levels of ID2 and COX-2 in endometrial tissue of the experimental group were significantly higher than those of the control group $(\mathrm{p}<0.05)$, and the difference was statistically significant $(\mathrm{p}<0.05)$, as depicted in fig. 2 .

Compared with the control group, the levels of VEGF, TNF- $\alpha$, IL-1 $\beta$ and CA 125 in the experimental group were significantly higher than those in the control group $(\mathrm{p}<0.05)$, as shown in fig. 3 .

In the endometrial tissues of the experimental group, ID2 was positively correlated with VEGF, IL-1 $\beta$ and CA 125 , while COX-2 was positively correlated with IL-1 and CA 125 , with statistically significant differences $(p<0.05)$, as shown in Table 2. The results showed that ID2 and COX-2 in endometrial tissue had high predictive value for clinical diagnosis of endometrial polyps, among which the sensitivity of ID2 was $87.32 \%$, specificity was $64.88 \%$ and truncation value was 1.68 . The sensitivity and specificity of COX-2 were $93.15 \%, 84.33 \%$, and the truncation value was 2.03, as shown in Table 3.

Endometrial polyps can cause chronic inflammatory changes in the internal environment of pelvic inflammatory disease, resulting in irregular menstruation or postmenopausal vaginal bleeding. Its occurrence and development can lead to a variety of adverse clinical outcomes ${ }^{[8]}$. Noninvasive investigations

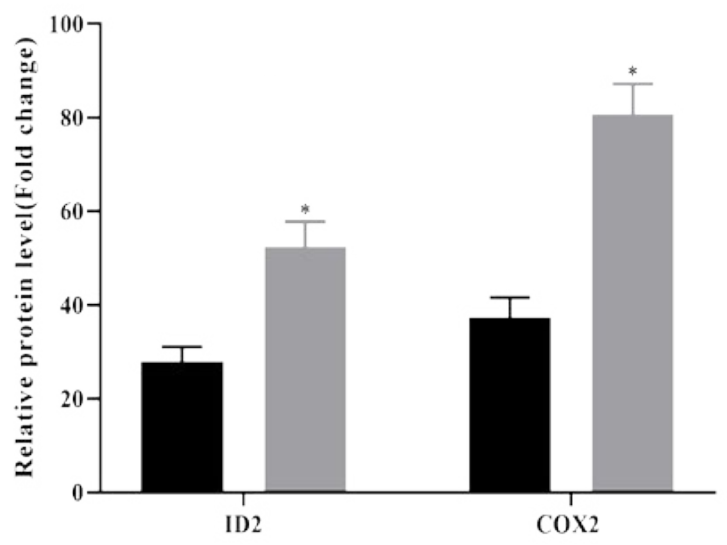

Fig. 1: Comparison of ID2 and COX-2 mRNA expression in endometrial tissues between the two groups. control group

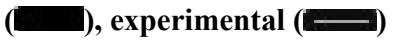

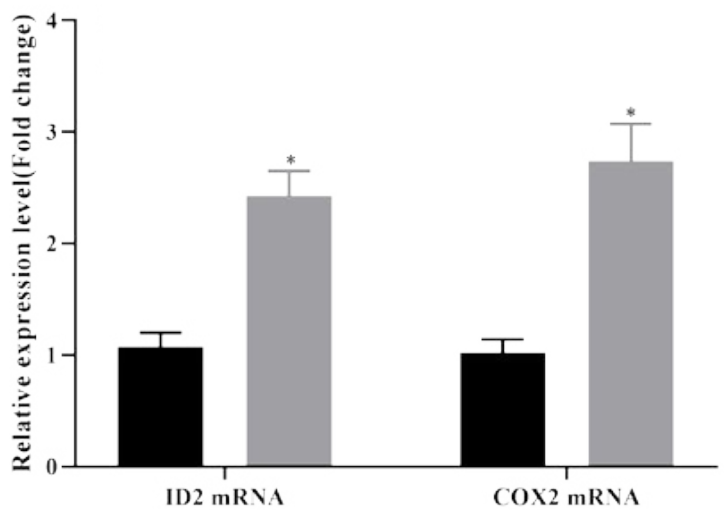

Fig. 2: Comparison of ID2 and COX2 protein levels in endometrial tissue between the two groups; control group

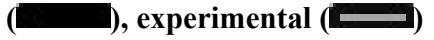


such as transvaginal ultrasonography, with the use of 3-dimensional ultrasonography remain the mainstay of first-line investigation. At present, hysteroscopic surgery is used to remove endometrial polyps, but there is a high recurrence rate after Hysteroscopic resection is the most effective management for endometrial polyps and allows histologic assessment. Preutthipan et al. reported that the recurrence rate can reach $15 \%{ }^{[9]}$. Studies have shown that the changes of cell biology related factors are related to the pathogenesis of endometrial polyps, which can accelerate the infiltration process of glandular cells by affecting the proliferation and invasion of glandular cells in endometriosis tissue, and eventually lead to the continuous deterioration of the disease ${ }^{[10]}$. Therefore, it is of great significance to seek specific molecular markers for the diagnosis and treatment of endometrial polyps. Studies have shown that ID2 and COX-2 are related to the pathogenesis of ovarian endometrial tumor, and both of them are directly or indirectly involved in the process of cell migration, invasion and angiogenesis ${ }^{[11]}$. There are few studies on the expression of ID2 and COX-2 in patients with endometrial polyps. Therefore, this study mainly discusses the expression levels of ID2 and COX-2 in endometrial tissues of patients with endometrial polyps, which can provide theoretical basis for the pathogenesis of endometrial polyps.

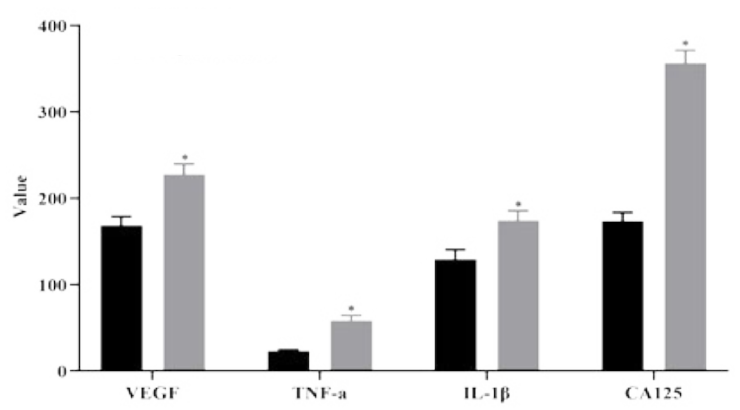

Fig. 3: Comparison of clinical indicators between the two groups control group ( $\square$ ), experimental $(\square)$

TABLE 2: RELATIONSHIP BETWEEN ID2, COX-2 AND CLINICAL INDEXES

\begin{tabular}{lcccc}
\hline \multirow{2}{*}{ Indexes } & \multicolumn{2}{c}{ ID2 } & \multicolumn{2}{c}{ COX-2 } \\
\cline { 2 - 5 } VEGF & $\mathbf{R}$ & $\mathbf{P}$ & $\mathbf{r}$ & $\mathbf{P}$ \\
TNF-a & 0.593 & 0.017 & -0.081 & 0.503 \\
IL-1B & -0.163 & 0.085 & -0.154 & 0.173 \\
CA 125 & 0.575 & 0.021 & 0.331 & 0.032 \\
\hline
\end{tabular}

TABLE 3: THE PREDICTIVE VALUE OF ID2 AND COX-2 FOR CLINICAL DIAGNOSIS

\begin{tabular}{lccc}
\hline Gene & Sensitivity & Specificity & Truncation value \\
\hline ID2 & $87.32 \%$ & $64.88 \%$ & 1.68 \\
COX-2 & $93.15 \%$ & $84.33 \%$ & 2.03 \\
\hline
\end{tabular}

ID2 is a member of the differentiation /DNA binding inhibitor family. It forms heterodimer by binding with basic helix loop helix transcription factors, resulting in ID2 deletion, affecting its binding with target genes, and then inhibiting the expression of related genes ${ }^{[10]}$. Studies have shown that abnormal expression of ID2 can promote the proliferation and migration of cancer cells, which is closely related to cell adhesion, protein glycosylation, cell invasion and angiogenesis ${ }^{[12]}$. Due to the similarity between endometrial polyps and cancer, the expression of ID2 mRNA was detected by qRT-PCR in the experimental group and the control group, and the protein expression level was detected by western blot assay. The results showed that the expression of ID2 mRNA and protein in the experimental group were higher than those in the control group, suggesting that ID2 was up-regulated in endometrial tissues of endometrial polyps. The relationship between ID2 in the endometrial tissue of the experimental group and the clinical indicators of the patients was observed, and the results showed that ID2 in the endometrial tissue of the experimental group was positively correlated with VEGF, IL-1 $\beta$ and CA 125, among which the high expression of VEGF can increase the infiltration capacity of heterotopic gland cells ${ }^{[13]}$. IL$1 \beta$ and CA 125 are highly expressed in patients with endometrial polyps, which can improve the adhesion ability of glandular cells by damaging mitochondria in endometrial polyps, and eventually damage the epithelial tissue of basement membrane seriously ${ }^{[14-16]}$. It is suggested that the expression of ID2 in endometrial tissue can be used as an index to predict the severity of endometrial polyps.

Cyclooxygenase includes COX-1 and COX-2 isozymes. COX-1 catalyses the release of prostaglandin E2 (dinoprostone) by cells at rest, which mainly maintains cell self-stability. COX-2 was almost not expressed under normal conditions. When inflammation and cell proliferation and differentiation appeared, it was induced by cytokines, growth factors and tumor promoters, and its expression could be rapidly increased by $8-10$ times. COX-2 is a rate-limiting enzyme of prostaglandin production, which is widely considered as one of the important inducible enzymes in inflammatory process ${ }^{[17]}$. Recent studies have found that the biological function of COX-2 can enhance the angiogenesis of subunit fibroblast growth factor and VEGF by stimulating the mitosis of human endothelial cells ${ }^{[18]}$. Based on this, the expression of COX-2 in endometrial tissues of patients with endometrial polyps and normal endometrial tissues was detected by qRT- 
PCR and western blot assay in this study. The results illustrated that the expression of COX-2 in endometrial tissues of patients with endometrial polyps in the experimental group was higher than that in the control group, indicating that COX-2 was highly expressed in endometrial tissues of patients with endometrial polyps. Further studies showed that COX-2 was positively correlated with IL-1 $\beta$ and CA 125, which suggested that COX-2 might be involved in the occurrence and development of endometrial polyps and accelerate the deterioration of the disease through the interaction with serum related factors. The results of this study indicated that ID2 and COX-2 in endometrial tissue have high predictive value for clinical diagnosis of endometrial polyps, indicating that ID2 and COX-2 in endometrial tissue can be used as predictive factors for clinical diagnosis of endometrial polyps. At the same time, this study analyzed the related factors of endometrial polyps by logistic regression analysis. The results showed that ID2 and COX-2 in endometrial tissue were risk factors for patients with endometrial polyps, indicating that both of them can interact and promote the development of the disease.

In summary, the high expression of ID2 and COX-2 in endometrial tissue is closely related to the occurrence and development of endometrial polyps. Both of them may be candidate specific target genes for endometrial polyps, and both of them can be used as markers for clinical diagnosis of endometrial polyps.

\section{Acknowledgements:}

This work was supported by The First Affiliated Hospital of Anhui Medical University and The First Affiliated Hospital of USTC, Division of Life Sciences and Medicine, University of Science and Technology of China.

\section{Conflict of interests:}

The authors declared no conflict of interest.

\section{REFERENCES}

1. Baskin GB, Smith SM, Marx PA. Endometrial hyperplasia, polyps, and adenomyosis associated with unopposed estrogen in rhesus monkeys (Macaca mulatta). Vet Pathol 2002;39:572-5.

2. Bulun SE, Gurates B, Fang Z, Tamura M, Sebastian S, Zhou $\mathrm{J}$, et al. Mechanisms of excessive estrogen formation in endometriosis. J Reprod Immunol 2002;55:21-33.

3. Bartley J, Mechsner S, Beutler C, Halis G, Lange J, Ebert AD. COX-2-expression in extragenital endometriosis lesions as a novel therapeutical approach? Zentralbl Gynakol 2003;125:252-5.

4. Watanabe H, Kanzaki H, Narukawa S, Inoue T, Katsuragawa $\mathrm{H}$, Kaneko Y, et al. Bcl-2 and Fas expression in eutopic and ectopic human endometrium during the menstrual cycle in relation to endometrial cell apoptosis. Am J Obstet Gynecol 1997; 176:360-8.

5. Maia Jr H, Casoy J. Non-contraceptive health benefits of oral contraceptives. Eur J Contracept Reprod Health Care 2008;13:17-24.

6. Fowler JM, Ramirez N, Cohn DE, Kelbick N, Pavelka J, BenShachar I, et al. Correlation of cyclooxygenase-2 (COX-2) and aromatase expression in human endometrial cancer: tissue microarray analysis. Am J Obstet Gynecol 2005;192:1262-71.

7. Kilico I, Kokcu A, Kefeli M, Kandemir B. Regression of experimentally induced endometriosis with a new selective cyclooxygenase-2 enzyme inhibitor. Gynecol Obstet Invest 2014;77:35-9.

8. Samoshkin NG, Yarmolinskaya MI, Polyakova VO. The efficacy of selective cyclooxygenase 2 inhibitors in the treatment of genital endometriosis. J Obstet Womens Dis 2018;67:52-60.

9. Preutthipan S, Herabutya Y. Hysteroscopic polypectomy in 240 premenopausal and postmenopausal women. Fertil Steril 2005;83(3):705-9.

10. Cho S, Park SH, Choi YS, Seo SK, Kim HY, Park KH, et al. Expression of cyclooxygenase-2 in eutopic endometrium and ovarian endometriotic tissue in women with severe endometriosis. Gynecol Obstet Invest 2010;69:93-100.

11. Maia H, Pimentel K, Correia Silva TM, Freitas LA, Zausner B, Athayde $\mathrm{C}$, et al. Aromatase and cyclooxygenase-2 expression in endometrial polyps during the menstrual cycle. Gynecol Endocrinol 2006;22:219-24.

12. Bulun SE, Zeitoun K, Sasano H, Simpson ER. Aromatase in aging women. Semin Reprod Endocrinol 1999;17:349-58.

13. Kim MR, Kim YA, Jo MY, Hwang KJ, Ryu HS. High frequency of endometrial polyps in endometriosis. J Am Assoc Gynecol Laparosc 2003;10:46-8.

14. Kesim MD, Aydin Y, Atis A, Mandiraci G. Long-term effects of the levonorgestrel-releasing intrauterine system on serum lipids and the endometrium in breast cancer patients taking tamoxifen. Climacteric 2008;11:252-7.

15. Dassen H, Punyadeera C, Kamps R, Delvoux B, Van Langendonckt A, Donnez J, et al. Estrogen metabolizing enzymes in endometrium and endometriosis. Hum Reprod 2007;22:3148-58.

16. Han J, Seo H, Choi Y, Lee C, Kim MI, Jeon Y, et al. Expression and regulation of inhibitor of DNA binding proteins ID1, ID2, ID3, and ID4 at the maternal-conceptus interface in pigs. Theriogenology 2018;108:46-55.

17. Sumida T, Ishikawa A, Nakano H, Yamada T, Mori Y, Desprez PY. Targeting ID2 expression triggers a more differentiated phenotype and reduces aggressiveness in human salivary gland cancer cells. Genes Cells 2016;21:915-20.

18. Sasaki-Saito N, Sawada Y, Ohmori S, Omoto D, Haruyama $\mathrm{S}$, Yoshioka $\mathrm{M}$, et al. Endometriosis in the setting of MuckleWells syndrome treated with an IL-1 $\beta$ antagonist. Eur J Dermatol 2017;27:442-3.

This is an open access article distributed under the terms of the Creative Commons Attribution-NonCommercial-ShareAlike 3.0 License, which allows others to remix, tweak, and build upon the work non-commercially, as long as the author is credited and the new creations are licensed under the identical terms

This article was originally published in a special issue, "Clinical Research in Pharmaceutical and Biomedical Sciences" Indian J Pharm Sci 2021:83(1)Spl issue1;70-74 